\title{
SEVERE VITAMIN D DEFICIENCY, FUNCTIONAL IMPAIRMENT AND MORTALITY IN ELDERLY NURSING HOME RESIDENTS
}

\author{
V. Centeno Peláez', L. Ausinn², M. Ruiz Mambrilla, M. Gonzalez-Sagrado, J.L. Pérez Castrillón ${ }^{5}$
}

\begin{abstract}
Background: Vitamin D deficiency is independently associated with functional impairment in elderly patients and is an independent risk factor for mortality. Objective: To assess the influence of severe vitamin D deficiency on the functional status, falls, fractures, cardiovascular morbidity and mortality and all-cause mortality in elderly nursing home residents. Design: Noninterventional, prospective, observational study. Setting: Nursing home. Participants: Non-dependent elderly. Measurements: Urea, creatinine, cholesterol, triglycerides, calcium, phosphorus, 25-OH vitamin $\mathrm{D}$, parathyroid hormone (PTH), and cystatin $\mathrm{C}$ were determined in blood and microalbuminuria in urine. All patients were administered the Katz Index of Independence in Activities of Daily Living (Katz ADL), the Tinetti Balance and Gait Evaluation, lower extremity function tests and the Mini-Mental State Examination. Patients were divided in two groups: those with 25 -hydroxyvitamin $\mathrm{D}<12.48 \mathrm{nmol} / 1$ (severe vitamin D deficiency) and those with 25-hydroxyvitamin $\mathrm{D} \geq 12.48 \mathrm{nmol} / 1$. Falls, clinical fractures, and cardiovascular morbidity and mortality and allcause mortality were recorded during the 20-month follow up. Results: Patients with severe vitamin D deficiency were older (87 \pm 7 vs. $83 \pm 7$ yrs., $\mathrm{p}=0.025)$ and more often female $(96 \%$ vs $4 \%, \mathrm{p}=0.028)$ and had lower levels and calcium and albumin and higher levels of PTH, a higher frequency of heart disease $(\mathrm{p}=0.02)$, and worse lower extremity function: Tinetti gait (10 \pm 2.39 vs 11.21 $\pm 1.44, \mathrm{p}=0.034)$, Tinetti balance $(1.83 \pm 1.11 \mathrm{vs} 2.5 \pm 1.19, \mathrm{p}=0.011)$. These patients had a non-significant higher number of falls and clinical fractures, and significantly greater mortality ( $29 \%$ vs $2 \%, \mathrm{p}=0.01)$. Conclusions: Non-dependent elderly nursing home residents with severe vitamin D deficiency have greater mortality, functional impairment of the lower extremities and a trend to a greater number of falls and clinical fractures.
\end{abstract}

Key words: Mortality, vitamin D, cardiovascular morbidity.

\section{Introduction}

Vitamin D levels have been associated with muscle function, with low levels increasing the risk of falls and fractures (1). Low levels of 25-hydroxyvitamin D $(25(\mathrm{OH})$ D) have been associated with an increased risk of falls in institutionalized elderly patients, with $25(\mathrm{OH}) \mathrm{D}$ levels $<40 \mathrm{nmol} / 1$ associated with reduced lower extremity function, while optimal function is obtained when levels are $>90-100 \mathrm{nmol} / \mathrm{l}$ : levels $>60 \mathrm{nmol} / 1$ are associated with a $20 \%$ reduction in the risk of falls (2). Studies have shown that vitamin D (800 IU of vitamin D3 daily) and calcium supplements reduce the risk of falls (3), although single high doses of vitamin D may increase the risk (4).

There is considerable evidence of the role of vitamin $\mathrm{D}$ in cardiovascular disease: studies have shown a

1. Servicio Medicina Interna. Hospital Santos Reyes Aranda de Duero. Burgos. Spain; 2. Residencia de Ancianos Parquesol. Valladolid. Spain; 3. Centro de Rehabilitación y Lenguaje. Valladolid. Spain; 4. Unidad de Investigación. Hospital Universitario Río Hortgea. Valladolid; 5. Servicio Medicina Interna. Hospital Universitario Rio Hortega. University of Valladolid. Spain

Corresponding Author: José Luis Pérez Castrillón, Servicio de Medicina Interna, Hospital Universitario Río Hortega, c/ Dulzaina 2, 47012 Valladolid. Spain, E-mail: castrv@terra.com, Phone: 34983420400, Fax: 34983331566 relationship with hypertension $(5,6)$, coronary disease $(7,8)$, cerebrovascular disease $(9)$, heart failure $(6)$, vascular disease (10) and, specifically, peripheral arterial disease (11), in addition to a relationship with renal disease (5). In addition, vitamin D deficiency has also been associated with increased mortality, especially cardiovascular mortality. A study in postmenopausal Japanese women examined the relationship between low 25(OH)D levels and low bone mineral density with increased mortality (12) and showed that $47 \%$ of patients had low levels of vitamin D and that the most frequent causes of death were cardiovascular events $(28 \%)$ and cancer $(21 \%)$. A study in Caucasian southern Californian adults evaluated the relationship between 25-hydroxyvitamin D, 1,25-dihydroxyvitamin $\mathrm{D}$ and parathyroid hormone (PTH) with cardiovascular mortality. The study found that $14 \%$ of patients had levels of $25(\mathrm{OH}) \mathrm{D}<75 \mathrm{nmol} / 1$ and $3 \%$ had levels $<50$ $\mathrm{nmol} / \mathrm{l}$. High levels of 1,25-dihydroxyvitamin D had a protective effect on cardiovascular mortality, while high PTH levels increased the risk of cardiovascular disease. After adjusting for age and multiple covariates (including renal function) no significant association between 
25-hydroxyvitamin D, 1,25-dihydroxyvitamin D, PTH and cardiovascular mortality was found (13). Another study evaluated the effects of low levels of calcitriol as a predictor of mid-term mortality in patients attending a specialized heart disease centre and found that low calcitriol levels were a predictor of mid-term mortality (14) and that $67 \%$ of patients with low levels had heart failure, $64 \%$ hypertension, $33 \%$ coronary artery disease, $20 \%$ diabetes and $17 \%$ renal failure after a one-year follow up. In contrast, other authors suggest that, although observational studies have shown an association between low levels of 25(OH)D and a wide range of acute and chronic disorders, there are no causal data that indicate vitamin D levels are a marker of disease (15).

The aim of this study was to assess the influence of severe vitamin D deficiency on the functional status, falls and fractures, cardiovascular morbidity and mortality, and all-cause mortality in elderly nursing home residents.

\section{Materials and Methods}

We made a non-interventional, prospective, observational cohort study in non-dependent elderly residents of the Parquesol nursing home (Valladolid). Inclusion criteria were age $\geq 80$ and residence in the nursing home. Exclusion criteria were people who were bedridden or had diminished mobility that precluded functional testing and those who did not wish to participate.

At inclusion, blood was extracted from all participants and a urine sample was collected. Samples were collected between 8 and 9 am and were processed immediately. Samples were deposited as serum $(1 \mathrm{ml})$ and plasma $(1 \mathrm{ml})$. The following determinations were made: urea, creatinine, total cholesterol, triglycerides, glucose, calcium, phosphorous and microalbuminuria using a Hitachi 917 automated analyser. Parathyroid hormone (PTH) was measured by electrochemiluminescence ( ${ }^{\circledR}$
Roche Diagnostics $\mathrm{GmbH}$, Mannheim, Germany), 25(OH) D3 by high performance liquid chromatography and cystatin $C$ (a marker of renal function deterioration) by immunonephelometry ( $N$ Latex Cistatina C, Siemens Marburg $\mathrm{GmbH}$, Germany). The presence of cardiovascular diseases and treatments were also recorded. Falls were recorded for 20 months using the nursing home's own protocol. Clinical fractures and mortality were also recorded. Patients were divided in two groups: those with 25 -hydroxyvitamin $\mathrm{D}<12.48$ nmol/1 (severe vitamin D deficiency) and those with 25-hydroxyvitamin $\mathrm{D} \geq 12.48 \mathrm{nmol} / 1$.

Independence was measured using the Katz Index of Independence in Activities of Daily Living (Katz ADL) (16). The Tinetti Balance and Gait Evaluation was used to detect the risk of falls $(17,18)$. Lower extremity function was evaluated by examining the ability to stand with the feet together in the side-by-side, semi-tandem, and tandem positions, time to walk 8 feet, and time to rise from a chair and return to the seated position 5 times. These tests are predictors of falls, disability, institutionalization and death $(19,20)$. For accuracy, these tests were made using a Van Allen chronometer and a 3-metre tape measure

The study was approved by the Clinical Research Committee of the Hospital Universitario Río Hortega. Patients or their representatives gave written informed consent to participate in the study.

\section{Stastistical analysis}

The results are expressed as mean \pm standard deviation. Comparisons of the mean were made using the paired t-test and the Mann-Witney non-parametric U test. Correlations between variables were assessed using Pearson's $r$ test and Spearman's test. Mortality during the follow up period were assessed by logistic regression analysis: the variables included were the median age of

Table 1

Biochemical variables according to vitamin D levels

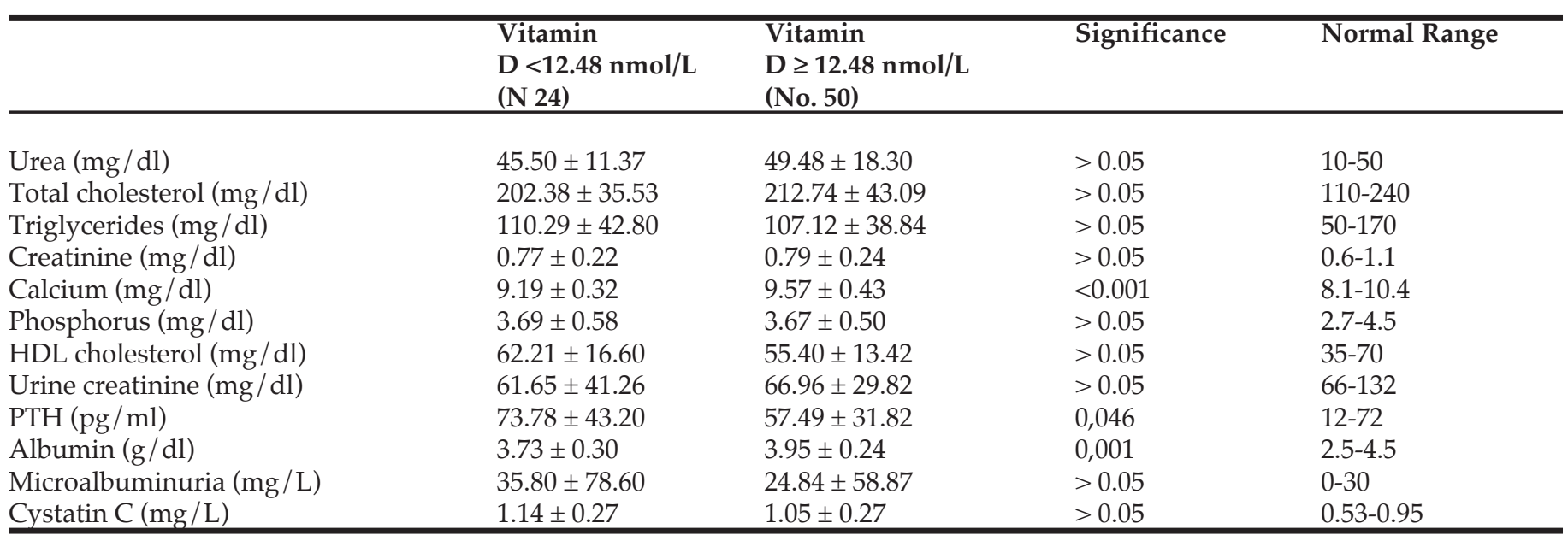


the study sample, sex and variables that were significant in the bivariate analysis. Statistical significance was established as $\mathrm{p} \leq 0.05$. The analysis was made using SPSS for Windows v. 15.0 (SPSS Inc. 1989-2006 Chicago IL, USA).

\section{Results}

Of the 183 institutionalized patients, 80 met the inclusion criteria, and levels of vitamin D were finally measured in 74 patients who were included in the final analysis. All had very low 25(OH)D levels, with a mean of $18.40 \pm 7.58 \mathrm{nmol} / \mathrm{L}$, a minimum of 9.10 and a maximum of $36.80 \mathrm{nmol} / \mathrm{L}$. Twenty-four patients had 25(OH)D levels $<12.48 \mathrm{nmol} / \mathrm{L}$ and 50 had levels $>12.48$ $\mathrm{nmol} / \mathrm{L}$.

Of the 74 patients analysed, $59(79.7 \%)$ were female, the mean age was $84 \pm 7$ years and the mean body mass index was $29 \pm 5 \mathrm{~kg} / \mathrm{m} 2$. Patients with 25(OH)D levels < $12.48 \mathrm{nmol} / \mathrm{L}$ were older $(87 \pm 7$ vs $83 \pm 7, \mathrm{p}=0.025)$ and more often female $(96 \%$ vs. $4 \%, \mathrm{p}=0.028)$ than patients with 25(OH)D levels $>12.48 \mathrm{nmol} / \mathrm{L}$.

Patients with $25(\mathrm{OH}) \mathrm{D}$ levels $<12.48 \mathrm{nmol} / \mathrm{L}$ had significantly lower calcium and albumin levels and significantly higher levels PTH levels (Table 1).The presence of heart disease, the number of heart diseases, and treatment with nitrates was more frequent in patients with 25(OH)D levels $<12.48 \mathrm{nmol} / \mathrm{L}$. (Table2).

No significant between-group differences in the Katz index were found ( $58.3 \%$ vs $73.5 \%, \mathrm{p}=\mathrm{NS})$.
Significant differences were found in the Tinneti gait and balance tests (Table 3). Falls ( $82.6 \%$ vs $62.5 \%, \mathrm{p}=$ NS) and fractures ( $17.4 \%$ vs $12.5 \%, \mathrm{p}=\mathrm{NS})$ were more frequent in patients with $25(\mathrm{OH}) \mathrm{D}$ levels $<12.48 \mathrm{nmol} / \mathrm{L}$ during the 20 months follow up, but the differences were not significant. Mortality during the follow-up was significantly higher in patients with $25(\mathrm{OH}) \mathrm{D}$ levels $<12.48 \mathrm{nmol} / \mathrm{L}(29 \%$ vs $2 \%$, p. $=0.001)$. Cystatin C (a marker of renal function and cardiovascular risk) was significantly higher in patients who died during the follow up compared with survivors $(1.33 \pm 0.31$ vs $1.04 \pm$ $0.25, \mathrm{p}=0.001)$.

The following variables were entered into the logistic regression analysis to assess the factors that independently predicted mortality: age, sex, vitamin D and cystatin C. Only vitamin D levels $<12.48 \mathrm{nmol} / \mathrm{L}$ (19.7, $\mathrm{p}=0.024,95 \%$ CI 1.48-261.53) remained as an independent factor of mortality (Table 4).

\section{Discussion}

The patients included in this study had very low levels of 25(OH)D: all patients had vitamin D insufficiency and most had vitamin D deficiency. Possible explanations may include the time of sample taking (May), and the patients were nursing home residents with less exposure to sunlight, or that the nutritional intake of vitamin D was not sufficient. Levels of $25(\mathrm{OH}) \mathrm{D}$ were lower than that found in a study of elderly female nursing home residents in Lleida (Spain) which found that $90 \%$ of

Table 2

Cardiovascular disease and therapy according to vitamin D levels

\begin{tabular}{|c|c|c|c|c|}
\hline & & $\begin{array}{l}\text { Vitamin } \\
\mathrm{D}<12.48 \mathrm{nmol} / \mathrm{L} \text { (N 24) }\end{array}$ & $\begin{array}{l}\text { Vitamin } \\
\mathrm{D} \geq 12.48 \mathrm{nmol} / \mathrm{L} \text { (N 50) }\end{array}$ & Significance \\
\hline \multirow{4}{*}{$\begin{array}{l}\text { Associated } \\
\text { cardiovascular diseases }\end{array}$} & Hypertension & $15(62.5 \%)$ & $28(56 \%)$ & NS \\
\hline & Dyslipidaemia & $3(12.5 \%)$ & $7(14 \%)$ & NS \\
\hline & Cerebrovascular disease & $4(16.7 \%)$ & $4(8 \%)$ & NS \\
\hline & Heart disease & $8(33.3 \%)$ & $4(8 \%)$ & 0.015 \\
\hline \multirow{4}{*}{$\begin{array}{l}\text { Number of associated } \\
\text { cardiovascular diseases }\end{array}$} & & 1 & $10(41.7 \%)$ & $20(40 \%)$ \\
\hline & 2 & $3(12.5 \%)$ & $14(28 \%)$ & \\
\hline & 3 & $6(25 \%)$ & $1(2 \%)$ & \\
\hline & 4 & 0 & $1(2 \%)$ & \\
\hline Drugs & Antiplatelet agents & $7(29.2 \%)$ & $11(22 \%)$ & $>0.05$ \\
\hline \multirow{5}{*}{$\begin{array}{l}\text { Number of cardiovascular } \\
\text { drugs }\end{array}$} & 0 & $5(20.8 \%)$ & $17(34 \%)$ & $>0.05$ \\
\hline & 1 & $6(25 \%)$ & $16(32 \%)$ & \\
\hline & 2 & $9(37.5 \%)$ & $15(30 \%)$ & \\
\hline & 3 & $4(16.7 \%)$ & $1(2 \%)$ & \\
\hline & 4 & 0 & $1(2 \%)$ & \\
\hline
\end{tabular}


Table 3

Functional tests according to level of vitamin D

\begin{tabular}{|c|c|c|c|}
\hline & $\begin{array}{l}\text { Vitamin } \\
\mathrm{D}<12.48 \mathrm{nmol} / \mathrm{L} \text { (N 24) }\end{array}$ & $\begin{array}{l}\text { Vitamin } \\
\mathrm{D} \geq 12.48 \mathrm{nmol} / \mathrm{L} \text { (N 50) }\end{array}$ & Significance \\
\hline Tinetti gait & $10.00 \pm 2.39$ & $11.21 \pm 1.44$ & 0.034 \\
\hline Balance & $1.83 \pm 1.11$ & $2.57 \pm 1.19$ & 0.011 \\
\hline Gait & $1.87 \pm 1.06$ & $2.30 \pm 1.02$ & $>0.05$ \\
\hline
\end{tabular}

Table 4

Logistic regression and mortality

\begin{tabular}{llll}
\hline Variable & Significance & Exp(b) & 95\% CI \\
\hline & & & $0.031-9.89$ \\
Sex & 0.690 & 0.557 & $0.121-19.23$ \\
Age & 0.744 & 1.525 & $0.502-59.69$ \\
Cistatin C & 0.163 & 5.437 & $1.48-261.53$ \\
Vitamin D & 0.024 & 19.687 & \\
\hline
\end{tabular}

patients had $25(\mathrm{OH})$ levels $<50 \mathrm{nmol} / \mathrm{L}$ and $47 \%$ had levels $<25 \mathrm{nmol} / \mathrm{L}$, although samples were collected in late summer (21).

Patients with $25(\mathrm{OH}) \mathrm{D}<12.48 \mathrm{nmol} / \mathrm{L}$ were significantly more often female and significantly older, and had significantly higher levels of PTH, which could explain the greater morbidity and mortality in these patients, and significantly lower levels of calcium and albumin.

Patients with 25(OH)D levels $<12.48 \mathrm{nmol} / \mathrm{L}$ had significantly more previous heart disease, and nonsignificantly higher levels of other cardiovascular diseases and risk factors. Patients with $25(\mathrm{OH}) \mathrm{D}$ levels $<12.48 \mathrm{nmol} / \mathrm{L}$ had a significantly higher level of nitrates. Greater nitrate consumption in this group could act as a protective factor against fractures and might explain why no significant differences in the number of fractures between groups were found (22). As stated in the introduction, 25(OH)D levels $<50 \mathrm{nmol} / 1$ have been associated with an increased prevalence of coronary artery disease $(7,8)$ and lower levels of $25(\mathrm{OH}) \mathrm{D}$ have been found in patients with heart failure compared with the healthy population (6).

Patients with 25(OH)D levels $<12.48 \mathrm{nmol} / \mathrm{L}$ had a greater degree of dependence. Although no significant differences were found for the Katz index, patients with $25(\mathrm{OH}) \mathrm{D}$ levels $<12.48 \mathrm{nmol} / \mathrm{L}$ had significantly worse scores in the Tinetti gait and balance tests, signifying worse function. Severe $25(\mathrm{OH}) \mathrm{D}$ deficiency has been related to muscle weakness (1), and levels $<40 \mathrm{nmol} / \mathrm{L}$ have been associated with reduced lower extremity function (2). A higher level of dependency and loss of function predisposes to an increased risk of falls and fractures, which were very common in both study groups, but more frequent in patients with $25(\mathrm{OH}) \mathrm{D}$ levels $<12.48 \mathrm{nmol} / \mathrm{L}$, although the differences were not statistically significant, possibly because both groups had very low levels of vitamin D. Various studies have shown an association between vitamin D deficiency and impaired physical function in nursing home residents, although these studies found a higher level of vitamin D than those observed in our subjects, and the follow-up periods differed (23-25). However, not all studies are in agreement. Mathei et al (26) found no such association even though 35\% of the 367 subjects studied had a severe vitamin D deficiency.

There was significantly greater mortality in patients with $25(\mathrm{OH}) \mathrm{D}$ levels $<12.48 \mathrm{nmol} / \mathrm{L}(29.2 \%$ vs. $2 \%)$. In a study of subjects with a similar age to ours, Formiga et al (27) found no association between mortality and vitamin D levels.

Patients who died had significantly higher cystatin $C$ levels. As stated above, cystatin $C$ is a marker of renal function and cardiovascular risk and increased levels increase the risk of all-cause mortality and linearly increase the risk of cardiovascular mortality (28).

The main limitations of our study are the small sample size and the fact that all patients had low levels of vitamin D. The strengths of the study are the uniformity of the population studied and the complete record of falls and fractures.

In conclusion, severe vitamin $\mathrm{D}$ deficiency in was an independent risk factor for mortality in elderly nursing home residents, as shown by other reports (13, 14). However, our study shows that severe vitamin D deficiency was independently associated with functional impairment in elderly patients, predisposing them a higher number of falls. 


\section{References}

1. Rosen CJ. Vitamin D Insufficiency. N Engl J Med 2011; 364:248-254.

2. Bischoff-Ferrari HA, Dawson-Hughes B, Willett WC et al. Effect of vitamin D on falls: a meta-analysis. JAMA 2004; 291: 1999-2006.

3. Holick MF. Vitamin D Deficiency N Engl Med 2007; 357:266-281.

4. Sanders KM, Stuart AL, Williamson EJ, et al. Annual high dose vitamin D and falls and fractures in older women: a randomized controlled trial. JAMA 2010; 303: 1815-1822.

5. Zittermann A, Gummert JF. Nonclassical Vitamin D Actions. Nutrients 2010 2: 408-425.

6. Zittermann A. Vitamin D and disease prevention with special reference to cardiovascular disease. Prog Biophys Mol Biol. 2006; 92:39-48.

7. Kim DH Sabour S, Sagar UN, et al. Prevalence of hypovitaminosis D in cardiovascular diseases (from the National Health and Nutrition Examination Survey 2001 to 2004) Am J Cardiol 2008;102:1540-4.

8. Kendrick J Targher G, Smits G, Chonchol M. 25-hydroxyvitamin D deficiency is independently associated with cardiovascular disease in the Third National Health and Nutrition Examination Survey. Atherosclerosis 2009; 205:255-260.

9. Michos E. D, Reis JP, Post WS et al. 25-Hydroxyvitamin D deficiency is associated with fatal stroke among Whites but not Blacks: The NHANES-III linked mortality files. Nutrition 2012; 28: 367-371.

10. Zittermann A, Schleithoff SS, Reiner K. Vitamin D and vascular calcification. Curr Opin Lipidol 2007; 18:41-46.

11. Fahrleitner-Pammer A, Obernosterer A, Pilger E et al. Hypovitaminosis D, impaired bone turnover and low bone mass are common in patients with peripheral arterial disease. Osteoporos Int. 2005; 16: 319-324.

12. Kuroda T, Shiraki M, Tanaka S, Onta H. Contributions of 25-hydroxyvitamin

$\mathrm{D}$, comorbidities and bone mass to mortality in Japanese postmenopausal women. Bone 2009; 44: 168-172.

13. Jassal S. K, Chonchol M, von Mühlen D, Smits G, Barrett- Connor E. Vitamin D, Parathyroid Hormone, and Cardiovascular Mortality in Older Adults: The Rancho Bernardo Study. The American Journal of Medicine 2010; 123: 11141120

14. Zittermann A, Schleithoff SS, Frisch S et al. Circulating Calcitriol Concentrations and Total Mortality. Clinical Chemistry 2009; 55: 1163-1170.

15. Autier P, Boniol M, Mullie P (2014). Vitamin D status and ill health: a systematic review. Lancet Diabetes Endocrinol 2014;2:76-89.

16. Katz S, Ford AB, Moskowitz RW, Jackson BA, Jaffe MW. Studies of illness in the aged. The index of ADL: a standardized measure of biological and psychosocial function. JAMA 1963; 185: 914-919.
17. Roqueta C, De Jaime E, Miralles R, Cervera AM. Experiencia en la evaluación del riesgo de caídas. Comparación entre el test de Tinetti y Timed Up \&Go. Rev Esp Geriatr Gerontol 2007; 42:319-327.

18. Lázaro del Nogal M, González-Ramírez A, Palomo-Lloro A. Evaluación de riesgo de caídas. Protocolos de valoración clínica. Rev Esp Geriatr Gerontol 2005; 40(Supl 2): 54-63.

19. Guralnik JM, Simonscik EM, Ferrucci et al. A short physical performance battery assessing lower extremity function: association with self-reported disability and prediction of mortality and nursing home admission. J Gerontol. 1994;49: M85-94.

20. Guralnik JM, Ferrucci L, Simonsick EM, Selive ME, Wallace RB. Lowerextremity function in persons over the age of 70 years as a predictor of subsequent disability. N Engl J Med 1995; 332:556-561.

21. Martin Portela M. A. L, Mónico A. Comparative 25-OH-vitamin D level in institutionalized women older than 65 years from two cities in Spain and Argentina having a similar solar radiation index. Nutrition 2010; 26: 283-289.

22. Jamal SA, Reid LS, Hamilton CJ. The effects of organic nitrates on osteoporosis: a systematic review. Osteoporos Int 2013;24: 763-770.

23. Diekmann R, Winning K, Bauer JM et al. Vitamin D status and physical function in nursing home residents: a 1-year observational study. Z Gerontol Geriatr 2013; 46: 403-9.

24. Kojima G, Tomai A, Meseki K et al. Prevalence of vitamin D deficiency and association with functional status in newly admitted male veteran nursing home residents. J Am Geriatr Soc 2013; 61: 1953-7.

25. Houston DK, Tooze JA, Davis CC et al. Serum 25-hydroxivitamin D and physical function in older adults: the Cardiovascular Health Study All Stars. J Am Geriatr Soc 2011; 59: 1793-1801.

26. Mathei E, Van Pottelberg C, Bees B, Adriaensen W, Gruson D, Degryse JM. No relation between vitamin $\mathrm{D}$ status and physical performance in the oldest old: results from the Belfroid study. Age Ageing 2013; 42: 186-190.

27. Formiga F, Ferrer A, Mejido MJ, Boix L, Contra A, Puyol R, Octabaix study members. Low serum vitamin D is not associated with an increase of mortality in oldest old subjects: the Octabaix three-year follow-up study. Gerontology 2014: 60: 10-15.

28. Shastri S, Katz R, Rifkin DE et al. Kidney Function and Mortality in Octogenarians: Cardiovascular Health Study All Stars. J Am Geriatr Soc 2012; 60:1201-1207. 